\title{
COMPUTER TECHNOLOGY Computer administration of the Peabody Picture Vocabulary Test to young children
}

\author{
DAVID L. ELWOOD and CAROLYN L. CLARK \\ Quinco Consulting Center, Columbus, Indiana 47201
}

\begin{abstract}
Computer-controlled administration of the Peabody Picture Vocabulary Test to children between the ages of 4 and 13 years was shown to be feasible without the presence of a live examiner. Test-retest correlation coefficients were obtained in the range from .54 to .74 and were not significantly different from those obtained with manual administration in the PPVT standardization sample. Practice effects and IQ differences between the two forms of the test were nonsignificant.
\end{abstract}

Automated psychological testing is potentially a more efficient and economical procedure than is manual testing. Elwood (1972b) presented results that suggested automated Wechsler Adult Intelligence Scale (WAIS) testing was less costly than manual WAIS testing. A number of experiments have been reported on reliability and validity aspects of automated testing. High correlations, mostly above .90 , have been reported for automated test-retest designs with adults (Elwood, 1972b, 1973; Elwood \& Griffin, 1972), automated vs. manual testing designs with adults (Elwood, 1972a), both automated test-retest and automated vs. manual testing designs with retarded subjects (Elwood, 1972c; Overton \& Scott, 1972), and automated vs. manual testing designs with children (Knights, Richardson, \& McNarry, 1973).

It has been clearly established that automated psychological testing procedures can be used to gather reliable test data. Furthermore, other research reports suggest that experimental subjects accept automated testing sufficiently well that it may be feasible clinically to use it routinely with some classes of subjects (e.g., Evan \& Miller, 1969; Klinge \& Rodziewicz, 1976; Klingler, Johnson, \& Williams, 1976; Elwood, Note 1). Most published studies on automated testing have used adult subjects. More needs to be known about the usefulness of automated psychological testing procedures with children.

The purpose of this experiment was to investigate statistical properties and practical clinical aspects of the Peabody Picture Vocabulary Test (PPVT), (Dunn,

The research described in this article was supported by Grant MH 14864 from the National Institute of Mental Health and by a grant from the Bartholomew County Hospital Foundation. The authors wish to thank Thomas B. Orr and Theodore $M$. Sharpe for suggestions on the design of this study, and Frederick H. Kanfer and Robert L. Sprague for comments on the report describing the study. Requests for reprints should be sent to David L. Elwood, Quinco Consulting Center, 2075 Lincoln Park Drive, Columbus, Indiana 47201.
1965) when administered via computer to young children.

\section{METHOD}

\section{Subjects}

Seventy-six subjects between the ages of 4 and 13 years were recruited for this study via a newspaper article, radio announcements, notices posted in prominent locations at Quinco Consulting Center, and through personal contacts by members of the research staff. Volunteers were nonrandomly assigned to one of four experimental groups to maintain sex and age balance. Subjects assigned to Groups 1 and 2 ranged in age from 4 years to 6 years, 5 months and subjects in Groups 3 and 4 were ages 6 years, 6 months to 13 years. The groups were tested in counterbalanced order on Forms A and B of the PPVT, with subjects in Groups 1 and 3 tested in the A-B order, and those in Groups 2 and 4 in the B-A order. Any subject who did not yield a basal on both forms of the test was eliminated from the data analysis and was replaced by another subject of the same sex and age.

\section{Apparatus}

In the testing room, the subject sat at a counter top facing a rear-projection screen, speaker, microphone, and a response box that contained buttons labeled "Help" and "Start," and back-lighted push buttons numbered $1,2,3$, and 4 , arranged in a 2 by 2 matrix. Standard PPVT plates, available from American Guidance Service, Inc. (Publishers' Building, Circle Pines, Minnesota 55014) were used to prepare $35-\mathrm{mm}$ slides. The slides for the three sample items and Items 1-137 were contained in a 140-slide-capacity Kodak carousel: slides for Items 138-150 were held in a second carousel. Slides were rear-projected via a Kodak Ektagraphic remote-controlled projector onto the screen, onto which large digits were superimposed in the central corners of each picture in the 2 by 2 matrix. Audio messages were recorded in the voice of the second author and were presented from four Broadcast Electronics Spotmaster tape decks. A Digital Equipment Corporation PDP-12 computer, interfaced with a Universal Digital Controller, controlled the random access audio system and the slide projector. The PDP-12 was equipped with a Teletype (Model ASR-33) and was interfaced with an oscilloscope that, during testing, gave a status readout of the item number and correctness of response of the last item completed. A television camera mounted in the rear of the testing room permitted video monitoring of subjects throughout testing. 


\section{Procedure}

Upon arrival at the laboratory, the subject was greeted and accompanied to the testing room by the second author, who served as the experimenter. When the subject entered the testing room, the projector lamp was "on," and the digits 1 through 4 were visible in the center of the screen and on the push buttons of the response box. The experimenter first checked to determine if the subject could identify the digits. In the few cases of subjects who could not identify the digits, the experimenter determined that the subject could match the digits on the screen with the digits on the push buttons. All subjects met this minimal requirement for the utilization of the automated procedure. The function of the "Help" and the "Start" buttons were explained, and then the subject initiated the automated procedure by pressing the "Start" button. The experimenter remained in the testing room while the subject listened to recorded instructions and responded to three sample items, or until she was assured that the subject fully comprehended the instructions. The subject was then left alone in the testing room until the test was terminated (when the subject reached the discontinuation criterion of six incorrect responses in eight consecutive items) or until the "Help" button was activated.

Depressing the "Help" button sounded a tone in the adjoining laboratory for approximately $2 \mathrm{sec}$, produced a Teletype printout of the item number, halted accumulation of latency data, and activated a red signal light in clear view of the experimenter's office. The experimenter responded to the "Help" request by going to the testing room. When the subject was ready to proceed with testing, latency measurement was resumed by the subject's pressing the "Start" button.

Every subject began with three sample items followed by Item 1 of the test, and continued until reaching the discontinuation criterion. The test format was designed so that a slide change occurred as soon as a response was made to the previous item. A 3-sec delay after the slide change was followed by a signal tone to alert the subject that the stimulus word would follow. Following presentation of the stimulus word, the subject had as long as needed to respond. If a subject reached Item 138, a "short delay" audio message was presented to the subject, and the "Help" conditions were automatically invoked to alert the experimenter of the need to change the slide carousel. When this had been accomplished, the experimenter reactivated the system from the Teletype and testing was resumed. The test was automatically terminated when the discontinuation criterion was reached. At that point the subject heard an "end of test" audio message, and the experimenter was alerted via the "Help" conditions and a printed message on the Teletype.
After completion of the test, the subject was escorted out of the testing room and given a 5- to 10 -min rest period while a report of test results was printed out on the Teletype. The report included subject and test information (name, date of test, date of birth, age, and test form and number), an item-byitem tabulation (item number, latency, response choice, and score), and summary data of total latency, total raw score, and mean response time on correct and on incorrect responses. The rest period was followed by retesting on the alternate form.

Following each test the subject was asked if the test had been "more like work or like play," if it had been "easy or hard," and "long or short?" After completion of the second test, the subject was given a lollipop and then dismissed. Parents seeking information about test results were scheduled for a later appointment with a psychologist for test interpretation.

\section{RESULTS}

Seventy-six children were tested, all except one on both forms of the PPVT. One subject was excluded from the sample because she refused to complete the second form of the test, and five other children were excluded because their scores on at least one form of the test fell below the extrapolated norms as provided in the PPVT manual. Data on the remaining 70 subjects were included in the analyses.

\section{IQ Analyses}

IQ data were analyzed to resolve questions relating to (1) differential adaptation to the automated procedure based on age, (2) practice effects (first vs. second test results), (3) comparable difficulty of the two forms of the test, and (4) sex differences. Table 1 summarizes the group mean IQs, standard deviations, and correlation coefficients for the four experimental groups and for combinations of the group data.

IQ data were analyzed by combining Groups 1 and 3 (Forms A-B order of testing) and Groups 2 and 4 (Forms B-A order of testing) and submitting these data to a Latin square design (Edwards, 1972, p. 319). There were no significant differences for groups (A-B vs.

Table 1

Group Mean IQs, Standard Deviations, and Correlation Coefficients

\begin{tabular}{|c|c|c|c|c|c|c|c|c|c|c|}
\hline \multirow[b]{2}{*}{ Group } & \multirow{2}{*}{$\begin{array}{c}\text { Mean } \\
\text { Age }\end{array}$} & \multirow{2}{*}{$\begin{array}{l}\text { Test } \\
\text { Order }\end{array}$} & \multirow[b]{2}{*}{$\mathrm{N}$} & \multicolumn{2}{|c|}{ First Test } & \multicolumn{2}{|c|}{ Second Test } & \multirow{2}{*}{$\begin{array}{c}\text { IQ } \\
\text { Difference }\end{array}$} & \multirow[b]{2}{*}{ r } & \multirow{2}{*}{$\begin{array}{c}\text { Corrected } \\
\mathbf{r} \dagger\end{array}$} \\
\hline & & & & IQ & SD & IQ & $\mathrm{SD}$ & & & \\
\hline 1 & $5-2$ & $A-B$ & 15 & 96.9 & 21 & 100.4 & 22 & 3.5 & .81 & $.59 * *$ \\
\hline 2 & $5-2$ & B-A & 15 & 101.5 & 30 & 106.7 & 20 & 5.2 & .87 & $.60^{* *}$ \\
\hline 3 & $9-2$ & A-B & 20 & 107.3 & 17 & 107.5 & 18 & .2 & .82 & $.76^{*}$ \\
\hline 4 & $9-6$ & B-A & 20 & 114.9 & 22 & 112.0 & 18 & -2.9 & .86 & $.75^{*}$ \\
\hline 1 and 2 & $5-2$ & $\begin{array}{l}\text { A-B } \\
\text { B-A }\end{array}$ & 30 & 99.2 & 26 & 103.5 & 22 & 4.3 & .82 & $.54^{*}$ \\
\hline 3 and 4 & $9-4$ & $\begin{array}{l}\text { A-B } \\
\text { B-A }\end{array}$ & 40 & 111.1 & 20 & 109.7 & 18 & -1.4 & .84 & $.74^{*}$ \\
\hline $\begin{array}{l}1 \text { and } 3 \\
2 \text { and } 4\end{array}$ & $\begin{array}{l}7-5 \\
7-8\end{array}$ & $\begin{array}{l}A-B \\
B-A\end{array}$ & $\begin{array}{l}35 \\
35\end{array}$ & $\begin{array}{l}102.8 \\
109.2\end{array}$ & $\begin{array}{l}20 \\
27\end{array}$ & $\begin{array}{l}104.4 \\
109.7\end{array}$ & $\begin{array}{l}20 \\
19\end{array}$ & $\begin{array}{r}1.6 \\
.5\end{array}$ & $\begin{array}{l}.82 \\
.86\end{array}$ & $\begin{array}{l}.68^{*} \\
.66^{*}\end{array}$ \\
\hline Total Sample & $7-6$ & $\begin{array}{l}\text { A-B } \\
\text { B-A }\end{array}$ & 70 & 106.0 & 24 & 107.1 & 20 & 1.1 & .83 & $.64^{*}$ \\
\hline
\end{tabular}

tCorrelation coefficients were corrected to reflect the range of ability included in the sample (Guilford, 1954, p. 392).

* Significant at the 01 level of confidence.

**Significant at the .02 level of confidence. 
Table 2

Comparison of Correlation Coefficients of This Study With Those of the PPVT Standardization Sample and of Overton and Scott

\begin{tabular}{|c|c|c|c|c|c|c|c|}
\hline This Study & $\mathrm{N}$ & $\begin{array}{c}\text { Corrected } \\
\mathrm{r}\end{array}$ & $\begin{array}{c}\text { Comparison } \\
\text { Group }\end{array}$ & $\mathrm{N}$ & I & $z$ & $\begin{array}{l}\text { Significance } \\
\text { of Difference }\end{array}$ \\
\hline $\begin{array}{l}\text { Groups } 1 \text { and } 2 \\
(\text { Mean age }=5-2)\end{array}$ & 30 & .54 & $\begin{array}{l}\text { Standardization Sample } \\
5 \text { Year Olds }\end{array}$ & 133 & .73 & 1.57 & n.s. \\
\hline $\begin{array}{l}\text { Groups } 3 \text { and } 4 \\
(\text { Mean age }=9-4)\end{array}$ & 40 & .74 & $\begin{array}{l}\text { Standardization Sample } \\
9 \text { Year Olds }\end{array}$ & 259 & .74 & .02 & n.s. \\
\hline $\begin{array}{l}\text { Total Sample } \\
\text { (Mean age }=7-6)\end{array}$ & 70 & .64 & $\begin{array}{l}\text { Standardization Sample } \\
7 \text { Year Olds }\end{array}$ & 100 & .74 & 1.26 & n.s. \\
\hline $\begin{array}{l}\text { Groups } 1 \text { and } 3 \\
\text { Test Order A-B }\end{array}$ & 35 & .68 & $\begin{array}{l}\text { Overton and Scott } \\
\text { Form } A^{*} \text { to Form } B^{*}\end{array}$ & 30 & .94 & 3.48 & .01 \\
\hline $\begin{array}{l}\text { Groups } 2 \text { and } 4 \\
\text { Test Order B-A }\end{array}$ & 35 & .66 & $\begin{array}{l}\text { Overton and Scott } \\
\text { Form } B^{*} \text { to Form } A^{*}\end{array}$ & 30 & .92 & 3.02 & .01 \\
\hline
\end{tabular}

*Automated

B-A), forms (A vs. B), or first vs. second order of testing.

First and second test mean IQ of the combined younger groups $(\mathrm{N}=30$, mean $\mathrm{IQ}=101)$ was not significantly different from the mean IQ of the combined older groups $(\mathrm{N}=40$, mean $I Q=110)$. Neither was the correlation coefficient for the combined younger groups $(\mathrm{r}=.54)$ significantly different than the correlation for the combined older groups $(r=.74)$.

\section{Correlational Data}

Tests for significance of difference between correlation coefficients obtained in this study and the correlation coefficients presented in the PPVT manual for comparable age groups of the standardization sample yielded no statistically significant values. However, correlation coefficients for automated-to-automated testing on the PPVT obtained by Overton and Scott (1972) with institutionalized retarded adults were significantly higher than those obtained in this study for comparable order-of-testing groups. Data on these correlation coefficient comparisons are presented in Table 2.

\section{Sex Differences}

Group mean IQs, standard deviations, and correlation coefficients are presented in Table 3 for groups redistributed according to sex. Combined Test 1 and Test 2 group mean IQ for all females $(\mathrm{N}=36$, mean $\mathrm{IQ}=101)$ was significantly lower than the two-test combined group mean IQ for all males $(\mathrm{N}=34$, mean
$I Q=112)[t(68)=2.36, p<.05]$. The difference between correlation coefficients for females $(\mathrm{r}=.55)$ and males $(\mathrm{r}=.74)$ was not statistically significant.

\section{Subject Reactions to Automated Testing}

Since the absence of a live examiner who can answer questions and reassure the child is potentially a liability in automated testing, it was felt that assessment of the children's requests for help would provide useful information on their adaptation to automated testing. During the first testing session, $62 \%$ of the subjects asked for help, while only $27 \%$ sought help during the second session $(z=4.17, p<.01)$.

Mean response times on correct items and incorrect items (3.1 and $6.5 \mathrm{sec}$, respectively) were significantly different $[t(139)=9.75, p<.001]$.

Of the 140 occasions ( 70 subjects times 2 tests each) when children were asked whether the activity was "more like work or like play," 122 responses were obtained in the suggested dichotomy. Of these, $40 \%$ defined the task as work, while $60 \%$ classified it as being more like play. Assuming a .5 probability for each answer, the percentages were significantly different $(\mathrm{z}=2.21, \mathrm{p}<.01)$.

In evaluating the relative length of the procedure, 133 cases were recorded in the long-short dichotomy, with $54 \%$ of the responses being long and $46 \%$ being short, a nonsignificant difference from expected proportions of .5 .

Seventy-nine percent (111 of 140) of responses to

Table 3

Group Mean IQs, Standard Deviations, and Correlation Coefficients for Groups Divided According to Sex

\begin{tabular}{|c|c|c|c|c|c|c|c|c|c|}
\hline \multirow[b]{2}{*}{ Group } & \multirow[b]{2}{*}{ Sex } & \multirow[b]{2}{*}{$\mathrm{N}$} & \multicolumn{2}{|c|}{ First Test } & \multicolumn{2}{|c|}{ Second Test } & \multirow{2}{*}{$\begin{array}{c}\text { IQ } \\
\text { Difference }\end{array}$} & \multirow[b]{2}{*}{ I } & \multirow{2}{*}{$\begin{array}{c}\text { Corrected } \\
\text { I }\end{array}$} \\
\hline & & & IQ & SD & IQ & $\mathrm{SD}$ & & & \\
\hline 1 and 2 & $\begin{array}{l}\text { Female } \\
\text { Male }\end{array}$ & $\begin{array}{l}16 \\
14\end{array}$ & $\begin{array}{r}91.7 \\
107.6\end{array}$ & $\begin{array}{l}27 \\
23\end{array}$ & $\begin{array}{r}95.9 \\
112.2\end{array}$ & $\begin{array}{l}22 \\
17\end{array}$ & $\begin{array}{l}4.2 \\
4.6\end{array}$ & $\begin{array}{l}.78 \\
.83\end{array}$ & $\begin{array}{l}.41^{*} \\
.70\end{array}$ \\
\hline 3 and 4 & $\begin{array}{l}\text { Female } \\
\text { Male }\end{array}$ & $\begin{array}{l}20 \\
20\end{array}$ & $\begin{array}{l}106.6 \\
115.5\end{array}$ & $\begin{array}{l}21 \\
20\end{array}$ & $\begin{array}{l}106.5 \\
112.9\end{array}$ & $\begin{array}{l}17 \\
19\end{array}$ &  & $\begin{array}{l}.79 \\
.89\end{array}$ & $\begin{array}{l}.66 \\
.83\end{array}$ \\
\hline All & $\begin{array}{l}\text { Female } \\
\text { Male }\end{array}$ & $\begin{array}{l}36 \\
34 \\
\end{array}$ & $\begin{array}{l}100.0 \\
112.3\end{array}$ & $\begin{array}{l}25 \\
21\end{array}$ & $\begin{array}{l}101.8 \\
112.6\end{array}$ & $\begin{array}{l}20 \\
18\end{array}$ & $\begin{array}{r}1.8 \\
.3\end{array}$ & $\begin{array}{l}.80 \\
.85\end{array}$ & $\begin{array}{l}.55 \\
.74\end{array}$ \\
\hline
\end{tabular}

*Not significant. All other corrected $r$ values are significant at the .01 level. 
the question of easy vs. hard were in the suggested dichotomy, while $19 \%$ of the responses were "both easy and hard." Automated testing was seen as significantly more easy than hard $(83 \%$ vs. $17 \%)(z=6.95, \mathrm{p}<.01)$. Children who responded "both easy and hard" were significantly more likely to be in the older group than in the younger group $(30 \%$ vs. $3 \%)(z=4.02, p<.01)$ (Edwards, 1972, p. 42).

\section{DISCUSSION}

This experiment demonstrated that it is feasible to use a computerized method to administer intelligence tests to young children. Subjects judged computerized testing as more like play than work, as easy rather than hard, and they judged testing session duration as "short" as often as they judged it "long." The requests of subjects for help decreased as they gained experience with the computerized system, and the time they spent studying test items increased as the items became more difficult. The IQ estimates obtained using this computerized system were essentially the same between first and second sessions, between Form $\mathrm{A}$ and Form B, and between older and younger subjects. It was also found that test-retest correlations for young vs. old and male vs. female subjects were not significantly different. By and large, our findings indicated that these subjects accepted, cooperated with, and adapted to the demands of computerized intelligence testing. Implicitly, "rapport" was established between these subjects and the automated system.

An unexpected finding was that male subjects obtained significantly higher IQs than female subjects. There were no apparent differences between the sexes in motivation or attitudes that might explain their differential IQ levels. Possibly, some experimental conditions inhibited the performances of female subjects. In this study the experimenter was female, the recorded voice for stimulus words was female, and the parent who brought the child for testing was most often the mother. Further research on computerized testing of young children may need to control these potential sources of influence on the subject's performance.

The failure of our automated test-retest correlations to be as high as those in other experiments (e.g., Elwood, 1973; Knights et al., 1973; Overton \& Scott, 1972) raises questions about the comparability of different automated systems and/or the influence of subjects' ages on test-retest reliability. The mean age of our subjects was 7.5 years, while the mean age of the Knights et al. (1973) subjects was 15.7 years. Also, the Knights et al. and Overton and Scott experiments used touchsensitive panels superimposed onto the screen where PPVT slides were projected. Subjects indicated their answers by touching one of the panels. The methodology used in this experiment (asking subjects to look at screen, select the picture that matched the stimulus word, determine the number associated with the picture, select the push button with a comparable number, and then press the push button) may have required a higher level of functioning.

One advantage of automated systems is their capability to collect some data that cannot be collected conveniently during manual testing. Routine monitoring of response time may lead to interactive testing systems that can branch to provide additional instructions. For example, if a computer-controlled testing system detected rapid incorrect responding, it might branch to a different audio message instructing the subject to take more time and study all alternatives before responding. Such a system could react promptly to subject behavior in much the same way that a live examiner does, but with greater objectivity and consistency.

\section{REFERENCE NOTE}

1. Elwood, D. L. Subject attitudes toward face-to-face vs. automated administration of intelligence tests. Unpublished manuscript. Columbus, Indiana: Quinco Consulting Center, 1977.

\section{REFERENCES}

Dunn, L. M. Expanded manual for the Peabody picture vocabulary test. Circle Pines, Minn: American Guidance Service, 1965. EDWARDs. A. L. Experimental design in psychological research. New York: Holt, Rinehart, \& Winston, 1972.

Elwood, D. L. Automated WAIS testing correlated with face-to-face WAIS testing: A validity study. International Journal of Man-Machine Studies, 1972. 4. 129-137. (a)

ELwood, D. L. Test-retest reliability and cost analyses of automated and face-to-face intelligence testing. International Journal of Man-Machine Studies, 1972, 4, 1-22. (b)

Elwood. D. L. Validity of an automated measure of intelligence in borderline retarded subjects. American Journal of Mental Deficiency. 1972, 77, 90-94. (c)

ELwooD. D. L. Reliability of automated intelligence testing using a three months test-retest interval. International Review' of Applied Psychology, 1973, 22, 157-163.

Elwood, D. L., \& Griffin, H. R. Individual intelligence testing without the examiner: Reliability of an automated method. Joumal of Consulting and Clinical Psychology. 1972, 38, 9-14.

Evan. W. M.. \& Miller, J. R. Differential effects on response bias of computer vs. conventional administration of a social science questionnaire: An exploratory methodological experiment. Behavioral Science, 1969, 14, 216-227.

GuILford, J. P. Psychometric methods (2nd ed.). New York: McGraw-Hill. 1954.

Klinge, V., \& Rodziewicz. T. Automated and manual intelligence testing of the Peabody picture vocabulary test on a psychiatric adolescent population. International Journal of Man-Machine Studies, 1976, 8, 243-246.

Klingler, D. E., Johnson, J. H., \& Williams, J. H. Strategies in the evaluation of an on-line computer-assisted unit for intake assessment of mental health patients. Behavior Research Methods \& Instrumentation, 1976, 8, 95-100.

Knights, R. M.. Richardson, D. H., \& MCNarRy, L. R. Automated versus clinical administration of the Peabody picture vocabulary test and the Raven coloured progressive matrices. American Journal of Mental Deficiency, 1973, 78. 223-225.

Overton, G. W., \& Scotr, K. G. Automated and manual intelligence testing: Data on parallel forms of the Peabody picture vocabulary test. American Joumal of Mental Deficiency, 1972, 76, 639-643.

(Received for publication March 28. 1977: revision accepted September 13. 1977.) 